\title{
Akış Enjeksiyon Analiz Yönteminde Dedektör Olarak Potansiyometrik Sensör Kullanarak Çevre Numunelerinde Kalsiyum İyonu Tayini
}

\author{
Adem Asan \\ Ondokuz Mayıs Üniversitesi, Fen Edebiyat Fakültesi, Kimya Bölümü, Samsun, Türkiye \\ aasan@omu.edu.tr (iD) \\ Makale gönderme tarihi: 21.12.2018, Makale kabul tarihi: 19.04.2019
}

\begin{abstract}
$\ddot{O} \mathbf{z}$
$\mathrm{Bu}$ çalı̧̧mada, su numunelerindeki kalsiyum derişiminin belirlenmesinde kullanılmak üzere ticari olarak satın alınan iyonofor madde ile $\mathrm{Ca}^{2+}$-seçici mikro potansiyometrik PVC-membran elektrot geliştirildi. Elektrotun potansiyometrik performans karakteristikleri belirlendi ve çevresel analizlere uygunluğu araştırıldı. Hazırlanan $\mathrm{Ca}^{2+}-$ seçici elektrot ile alınan ölçümlerde ana iyon çözeltisine karşı her 10 katlık kalsiyum iyonu konsantrasyonu değişimi için ortalama 23,5 mV'luk bir potansiyel farkı gözlendi. Elektrotun, $1 \times 10^{-1}-1 \times 10^{-5} \mathrm{~mol} \mathrm{~L}^{-1}$ derişim aralığında ana iyon çözeltisine karşı doğrusal davranış sergilediği, alkali ve toprak alkali metal iyonlarının yanında ana iyona karşı oldukça seçici olduğu belirlendi. Laboratuvarda mikro ölü hacme sahip akış hücreleri hazırlandı ve akış enjeksiyon analizi (AEA) sisteminde hareketli faz olarak $5 \times 10^{-5} \mathrm{M} \mathrm{CaSO}_{4}$ ve $\mathrm{MgSO}_{4} ; 1 \times 10^{-6} \mathrm{M} \mathrm{NaCl}, \mathrm{KNO}_{3}, \mathrm{LiNO}_{3}$ ve $\mathrm{NH}_{4} \mathrm{Cl}$ çözelti karışımı kullanılmış ve akış hızı: $1,0 \mathrm{~mL} \mathrm{dk}^{-1}$, enjeksiyon hacmi ise $20 \mu \mathrm{L}$ olarak belirlenmiştir. Geliştirilen bu elektrotların AEA sisteminde dedektör olarak kullanılması ile çevresel su numunelerinde kalsiyum iyonu tayini gerçekleştirildi. Ayrıca, su numunelerindeki kalsiyum tayini standart ekleme yöntemi ile de yapıldı ve tüm ölçümler potansiyometrik sonuçlarla karşılaştırmalı olarak verildi. Elde edilen sonuçlar, geliştirilen $\mathrm{Ca}^{2+}$-seçici mikro potansiyometrik PVC-membran elektrotun çevre numunelerindeki sularda kalsiyum iyonunun rutin tayininde etkin bir şekilde kullanılabileceğini göstermektedir.
\end{abstract}

Anahtar Kelimeler: Akış enjeksiyon analiz, çevre numunesi, kalsiyum, PVC-membran elektrot

\section{Determination of Calcium Ion in Environmental Samples Using a Potentiometric Sensor as a Detector in Flow Injection Analysis Method}

Abstract

In this study, $\mathrm{Ca}^{2+}$-selective potentiometric PVC-membrane electrode was developed with the commercially purchased ionophore substance to be used to determine calcium concentration in water samples. The potentiometric performance characteristics of the electrode were determined and their suitability for environmental analysis was investigated The measurements taken with the $\mathrm{Ca}^{2+}$-selective electrode indicated an average potential change of 23,5 $\mathrm{mV}$ per decade against the main ion concentrations. The electrode showed linear behavior against the main ion solution in the concentration range between $1 \times 10^{-1}-1 \times 10^{-5} \mathrm{~mol} \mathrm{~L}^{-1}$, and it was found to be highly selective against the main ion besides the alkali and alkaline earth metal ions. Micro dead volume flow cells were prepared in the laboratory and the calcium determination was made in environmental water samples by using the home-made electrode as a detector in the flow injection analysis (FIA) system. In the flow-injection analysis system (FIA), $5 \times 10^{-5} \mathrm{M} \mathrm{CaSO}_{4} \mathrm{ve}^{\mathrm{MgSO}} \mathrm{C}_{4} ; 1 \times 10^{-6}$ $\mathrm{M} \mathrm{NaCl}, \mathrm{KNO}_{3}, \mathrm{LiNO}_{3}$ ve $\mathrm{NH}_{4} \mathrm{Cl}$ solution mixture was used as the mobile phase. In this system, the flow-rate was set to $1,0 \mathrm{~mL} \mathrm{~min}^{-1}$ and injection volume $20 \mu \mathrm{L}$. In addition, calcium determination in water samples was performed by standard addition method and all measurements were compared with potentiometric results. The results show that the $\mathrm{Ca}^{2+}$-selective micro-potentiometric PVC-membrane electrode can effectively be used for routine determination of calcium ion in water in environmental samples.

Keywords: Flow injection analysis, environmental sample, calcium, PVC-membrane electrode

\section{GİRIŞ}

İyon-seçici elektrotlar (ISE), düşük maliyet, hızlı cevap, kolay kullanım ve tahribatsız ölçüm gibi temel avantajları nedeniyle birçok araştırma ve tıbbi laboratuvarda yaygin uygulamalara sahiptir. Kat1 temas uygun bir oranda bir grafit ve epoksi reçinesi karışımı kullanılarak hazırlanmıştır. $\mathrm{Bu}$ tip elektrotlarda, katı kontakt, algılama membranı için 
uygun bir yüzey sağlar. Algılayıc1 membran ve metalik iletken arasında iletken bir madde olarak katı kontakt kullanmak, uzatılmış ömür, sağlamlık, minyatür yapı ve düşük masraf gibi ISE'lere ekstra özellikler kazandırır. Son yıllarda, tüm katı kontaktlı iyon-seçici elektrotlar bu alanda yoğun bir şekilde kullanılmaktadır (Amini ve ark., 2003; Gallarda ve ark., 2003; Guiterrez ve ark., 2008; Gismera ve ark., 2009). Potansiyometrik sensörlerin kullanılmasının, üretim kolaylığ 1 , hızlı cevap, bulanık veya renkli çözeltilere uygulanabilme, yüksek hassasiyet, geniş doğrusal dinamik aralık, düşük maliyet ve yüksek seçicilik gibi iyon-seçici elektrotlar ile akıș enjeksiyon potansiyometrisinin (AEP) avantaj1 son yirmi y1lda iyi bilinmektedir (Cardwell ve ark., 1988; Yang ve ark., 1998; Hassan ve ark., 2007; Shamsipur ve ark., 2007).

Küçük derişimlerdeki mineral iyonlar sularda ve ekosistemlerde canlı yaşamını sürdürebilmesi için gereklidir. Bununla birlikte, bu minerallerin çeşitli organizmalarda yüksek derişimlerde birikmesi ekosistemin dengesini bozan bir etki olarak karşımıza çıkmaktadır. Bu mineral iyonlardan özellikle kalsiyum iyonu insan hayatı ve biyolojik aktivite için çok önemli bir parametredir. Sularda iyonik formda bol miktarda kalsiyum bulunur (Ahmad ve ark., 2018). Sulu ortamda kalsiyum iyonu konsantrasyonu tayini endüstri, içme suyu sertliği kontrolü, tıbbı teşhis ve gida kalite değerlendirmesi gibi birçok alanda büyük önem taşımaktadır (Alizadeh ve ark., 2016). Diğer taraftan kalsiyum, sulu ortamlarda, fizyolojik sivilarda, biyomateryallerde ve insan vücudunda en bol bulunan elementlerden biridir (Abramova ve ark., 2016; Zhang ve ark., 2015). Özellikle de kalsiyum iyonu insan yaşamındaki biyolojik aktiviteler için önemlidir ve çeşitli ortamlardaki analizi büyük önem taşır (Bogdanova ve ark., 2013). Akış-enjeksiyon analizinin durgun ortamdaki ölçümlere göre, örnekleme hızı, zaman, çok küçük örnek hacmi ile çalışılabilmesi, kesinliğinin daha yüksek olması ve elektrot yüzeyinin sürekli temizlenmesinin gerekli olmadığ gibi önemli avantajlara sahiptir (Ruzicka, 1992).

Çeşitli numunelerdeki kalsiyum tayini için spektroskopik teknikler (Hans, 2003; Ismail ve ark., 2011; Johns ve ark., 2014; Torres, 2014), s1v1 kromatografisi (Cardoni ve Coccioli, 1986), elektrokimyasal yöntem (Shiddiky ve Torriero, 2011), atomik absorpsiyon spektroskopisi (AAS) yöntemi (de Jesus ve ark., 2010), ICP-OES (Terrab ve ark., 2004; Deng ve ark., 2008) ve iyon-seçici elektrotlar (Silanikove ve erk., 2003; Lin ve ark. 2006; Tsioulpas ve ark., 2007; Hernandez ve ark., 2010) kullanılmaktadır. Tekrarlanabilirliği, hızı, maliyeti ve kolaylığı nedeniyle kalsiyum tayini için en yaygın kullanılan yöntem iyon-seçici elektrotların kullanıldığı yöntemdir (Abbas ve Magar, 2018). İyon-seçici elektrotların kullanıldı ̆̆1 potansiyometri, sürekli ve otomatik analizlerde kullanıma uygun bir tekniktir. İyon-seçici elektrotların en önemli uygulamaları klinik kimya alanındadır. Fakat son zamanlarda çevresel analizlerde, özellikle su ve toprak örnek analizlerinde yaygın olarak kullanılmaktadırlar. Su ve toprak karışımları gibi çoklu iyonik türleri içeren numunelerin analizlerinde iyon-seçici sensör dizilerinin kullanımı en iyi ve avantajlı ölçüm verilerini sağlamaktadır (Ruis ve Callao, 2001).

Bu çalışmada; çevre suyu numunelerindeki $\mathrm{Ca}^{2+}$ iyonunun tayini için ticari olarak satın alınan iyonofor madde ile $\mathrm{Ca}^{2+}$-seçici mikro potansiyometrik PVC-membran elektrot geliştirildi. Geliștirilen bu elektrotun akış enjeksiyon analiz sisteminde dedektör olarak kullanılması sonucu çeşitli su numunelerindeki $\mathrm{Ca}^{2+}$ iyonu başarı ile ölçülmüştür.

\section{MATERYAL VE METOD \\ Materyal}

Tetrahidrofuran (THF), yüksek molekül ağırlıklı polivinilklorür (PVC), o-nitrofeniloktileter (o-NPOE), grafit, Fluka (Bucks, Switzerland) firmasından, epoksi reçinesi (Ultrapur SU 2227 Victor (Italy) firmasından, sertleștirici (Desmodur RFE), polikarbonat blok Bayer AG (Germany) firmasından ve çalışmada kullanılan diğer bütün tuzlar (alkali ve toprak alkali metal tuzları v.b) Merck (Darmstadt, Germany) firmasından sağlandı. $\mathrm{Ca}$ IV iyonofor; (ETH 5234); N,N-Dicyclohexyl$\mathrm{N}^{\prime}, \mathrm{N}^{\prime}$-dioctadecyl-3-oxapentanamide, $\left(\mathrm{C}_{52} \mathrm{H}_{100} \mathrm{~N}_{2} \mathrm{O}_{3}\right)$ Merck (Darmstadt, Germany) firmasından sağlandı.

Potansiyel ölçümleri, sensör araştırma laboratuarımızda geliştirilen bilgisayar programı ile desteklenmiş çok kanallı potansiyometre cihazıyla gerçekleştirilmiştir. Potansiyel ölçümlerinde referans elektrot olarak, doygun kalomel elektrot (Russell, UK) kullanılmıştır. Akış enjeksiyon analizi ölçümleri, bilgisayar kontrollü şırınga tipi Lambda VITFIT marka bir pompa ve VI-CI marka otomatik enjeksiyon vanasından oluşmaktadır. Ayrıca enjeksiyonlarda Hamilton cam enjektör (100 $\mu$ L'lik) 
kullanılmıştır. Akış hücrelerinin hazırlanmasındaki delik açma, kesme ve yüzey düzeltme gibi işlemler için torna matkabı ve zımparası kullanılmıştır. Tartım işlemlerinde, Avery Berkel (Model VA 304) analitik terazi kullanılmıştır. Çözeltilerin hazırlanmasında kullanılan deiyonize su Millipore UV marka ultra deiyonize su cihazı kullanılarak sağlanmıştır.

Çalışmada hazırlanan elektrotların potansiyometrik performanslarının belirlenmesi için standart katyon çözeltileri kullanılmıştır. Standart stok çözeltiler, katyonların nitrat tuzlarından hazırlanmıștır. Bütün standart stok çözeltileri deiyonize su ile analitik saflıktaki maddelerden 0,1 $\mathrm{M}$ olacak şekilde hazırlanarak istenilen derişimlere seyreltilmiştir. Hazırlanan stok çözeltiler buzdolabında saklanmıştır.

\section{Metot}

İyon-seçici elektrotların hazırlanmasında önce, katı kontakt karışımı bir bakır tel üzerine kaplanmış ve daha sonra kuruyan bu katı kontakt yüzeyine hazırlanan PVC membran kokteyleri kaplanmıştır. Katı kontakt karışımı hazırlamak için; ağırlıç̧a \%50 grafit, \%35 epoksi reçinesi (Ultrapur SU 2227) ve $\% 15$ sertleștirici (Desmadur RFE) tartılarak THF çözücüsü içerisinde çözülmüştür. Uygun viskozite sağlandığında, daha önce hazırlanan bakır tel (yaklaşık 0,4-0,5 $\mathrm{mm}$ çap ve 5-10 $\mathrm{cm}$ uzunlukta) üzerine bu karışım 6-8 defa daldırılarak kaplanmış ve oda sicaklığında bir gece bekletilerek kullanıma hazır hale getirilmiştir. Şekil 1'de laboratuvarda hazırlanan bir $\mathrm{Ca}^{2+}$-seçici membran elektrot gösterilmektedir.

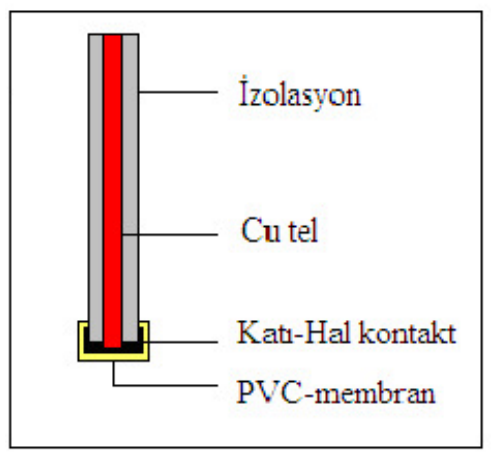

Şekil 1. Laboratuvarda hazırlanan bir $\mathrm{Ca}^{2+}$-seçici membran elektrot
Potansiyometrik ölçümlerde kullanılmak üzere; polikarbonit bloklar kesilmiş ve mikro torna uçları yardımıyla akış yolu $(0,5-0,7 \mathrm{~mm}$ çap ve $25 \mathrm{~mm}$ uzunlukta) ve sensörlerin yerleştirileceği silindirik kuyucuklar $(0,7-1 \mathrm{~mm}$ çap ve $5 \mathrm{~mm}$ derinlikte) oluşturulmuştur. Hazırlanan bu akış hücreleri içerisine laboratuvarda geliştirilen $\mathrm{Ca}^{2+}$-seçici mikro potansiyometrik PVC-membran elektrot referans elektrotla beraber yerleştirilmiş ve akış enjeksiyon sisteminde dedektör olarak kullanılmıştır. Kullanılan sistemin şematik gösterilimi Şekil 2'de olduğu gibidir.

Hazırlanan $\quad \mathrm{Ca}^{2+}$-seçici elektrotun potansiyometrik karakteristikleri (doğrusal çalışma aralığı, tayin limiti, tekrarlanabilirliği, seçiciliği, cevap zamanı ve $\mathrm{pH}$ çalışma aralı̆̆ı) durgun ortam ölçümleriyle belirlenmiştir. Elektrot, ölçüm alınmadığı zamanlarda kuru olarak oda sicaklığında saklanmış ve her ölçüm alınmadan önce ana iyon çözeltilerinde yarım saat kadar şartlandırılmıştır (doyurulmuştur). Durgun ortamlarda alınan ölçümlerde, elektrotun potansiyel değişimleri, iyonseçici elektrot ve referans elektrotun $20 \mathrm{~mL}$ 'lik çözeltiye aynı derinlikte daldırılmasıyla ölçülmüştür. Her ölçümden önce elektrotlar deiyonize su ile yıkanmıștır. Hazırlanan elektrot, akıș enjeksiyon analiz sisteminde dedektör olarak kullanılmıştır. Akış yolu üzerine yerleştirilen potansiyometrik akış hücreleri vasitasiyla $\mathrm{Ca}^{2+}$ iyonunun hizlı ve tekrarlanabilir tayini, düşük örnek hacimlerinde (20 $\mu \mathrm{L})$ gerçekleştirilmiştir. Hareketli faz olarak çeşitli karışımlar denendi. Bu denemeler sonucunda gerek temel bir base-line oluşturması ve gerekse elde edilen piklerin keskinliği nedeniyle $5 \times 10^{-5} \mathrm{M}$ $\mathrm{CaSO}_{4}, \mathrm{MgSO}_{4}$ ve $1 \times 10^{-6} \mathrm{M} \mathrm{NaCl}, \mathrm{KNO}_{3}, \mathrm{LiNO}_{3}$, $\mathrm{NH}_{4} \mathrm{Cl}$ çözeltilerinden oluşan karışım kullanılmıştır. Farklı hacimdeki numune ve akış hızı denemeleri sonucunda; enjeksiyon hacmi $20 \mu \mathrm{L}$ ve akıș hızı 1 $\mathrm{mL} \mathrm{dk}^{-1}$ olarak seçildi ve $1 \times 10^{-1}-1 \times 10^{-6} \mathrm{~mol} \mathrm{~L}^{-1}$ standart kalsiyum çözeltileri kullanılarak kalibrasyon grafiği çizildi. Çizilen bu grafik yardımıyla farklı çevre suyu numunelerindeki kalsiyum analizi gerçekleştirildi.

\section{BULGULAR VE TARTIŞMA}

Metot kısmında açıklandığ $\mathrm{Ca}^{2+}$-seçici PVC-membran elektrotlar hazırlandı ve elektrotlardan en iyi performans1 sergileyeni seçilerek potansiyometrik performans karakteristikleri belirlendi. Ca IV iyonofor; (ETH 


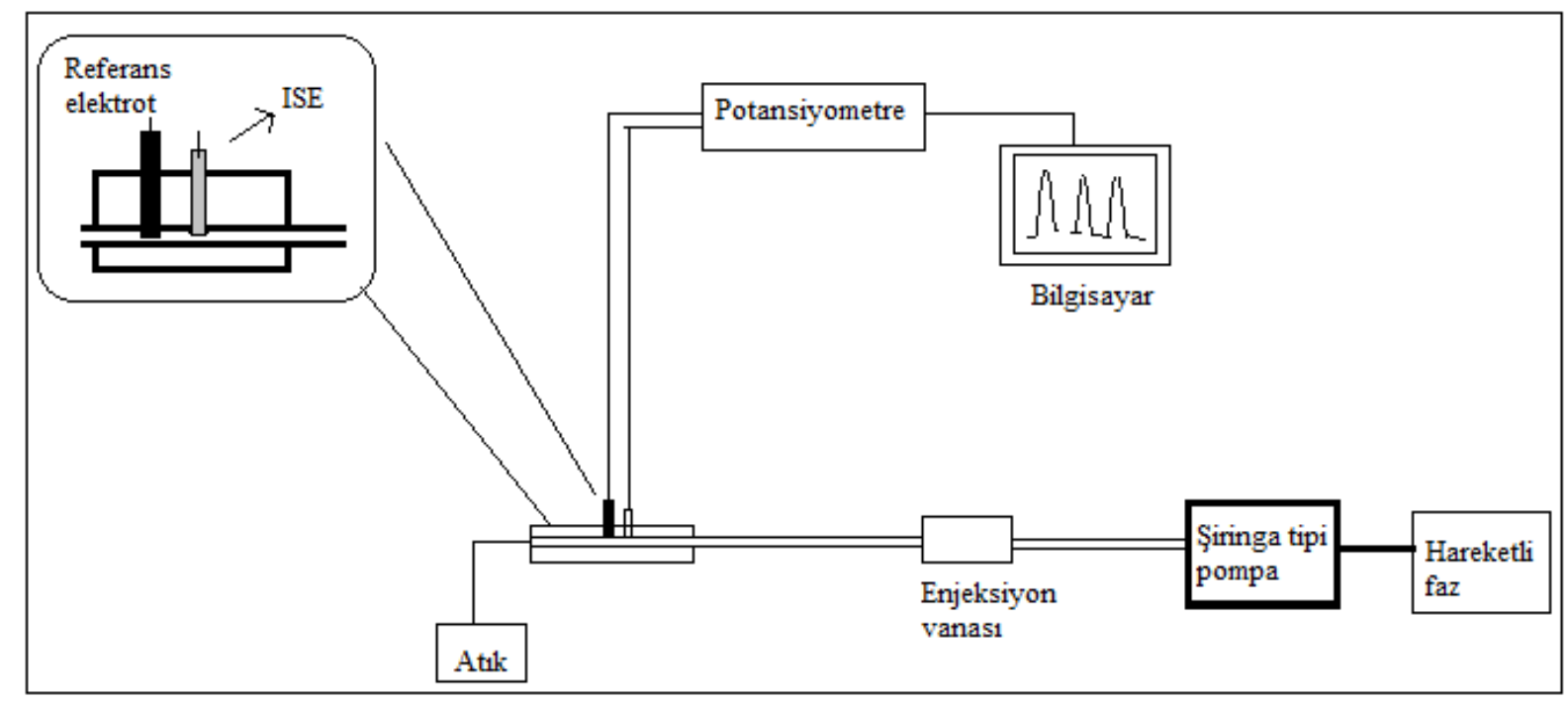

Şekil 2. Çalışmada kullanılan akış enjeksiyon analiz sisteminin şematik gösterilimi

5234); N,N-Dicyclohexyl-N',N'-dioctadecyl-3oxapentanamide, $\quad\left(\mathrm{C}_{52} \mathrm{H}_{100} \mathrm{~N}_{2} \mathrm{O}_{3}\right) \quad$ kullanilarak hazırlanan PVC-membran elektrotun potansiyometrik davranışı, derişimi $1 \times 10^{-6}-1 \times 10^{-1} \mathrm{M}$ arasında değişen standart katyon $\left(\mathrm{Mg}^{2+}, \mathrm{Li}^{+}, \mathrm{Na}^{+}\right.$, $\left.\mathrm{K}^{+}, \mathrm{NH}_{4}^{+}, \mathrm{Sr}^{2+}, \mathrm{Ba}^{2+}\right)$ çözeltileri kullanılarak test edildi. Elektrotların, diğer iyonlar yanında $\mathrm{Ca}^{2+}$ iyonuna karşı seçici olduğu, hızlı ve tekrarlanabilir cevap sergilediği gözlemlenmiştir. $\mathrm{Ca}^{2+}$-seçici PVCmembran elektrot hazırlamak için çeşitli membran bileşiminde kokteyl karışımları kullanılarak test edildi. En uygun bileşim olarak \%2 iyonofor, \%68 plastikleştirici, \%29 PVC ve \%1 KTPClPB karışımı belirlendi. Hazırlanan bu elektrot için performans özellikleri aşağıda verilmiştir. Şekil 3'te, $1 \times 10^{-6}$ $1 \times 10^{-1} \mathrm{M}$ derişim aralığındaki standart $\mathrm{Ca}^{2+}$ çözeltilerine (ölçümler düşük derişimden yüksek derişime ve sonra tekrar düşük derişime doğru alınmıştır) sırasıyla daldırılan $\mathrm{Ca}^{2+}$-seçici PVCmembran elektrotun potansiyometrik davranış1 görülmektedir.

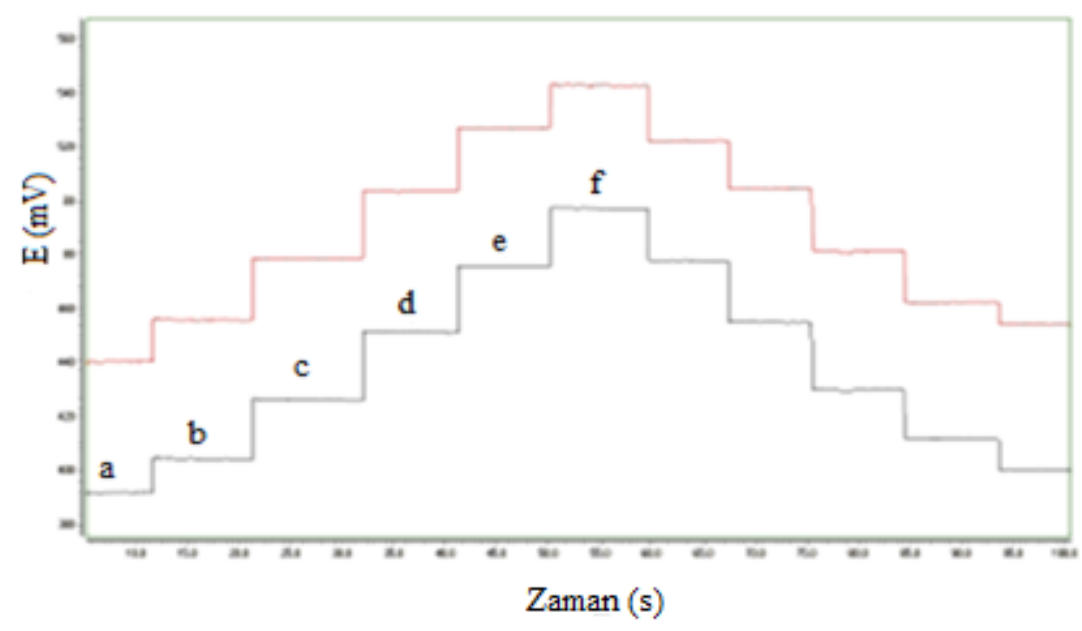

Şekil 3. $\mathrm{Ca}^{2+}$-seçici PVC-membran elektrota ait potansiyel-zaman grafiği $\left(\mathrm{a} ; 1 \times 10^{-6} \mathrm{M}, \mathrm{b} ; 1 \times 10^{-5} \mathrm{M}, \mathrm{c} ; 1 \times 10^{-4} \mathrm{M}\right.$, $\mathrm{d} ; 1 \times 10^{-3} \mathrm{M}$, e; $1 \times 10^{-2} \mathrm{M}, \mathrm{f} ; 1 \times 10^{-1} \mathrm{M} \mathrm{Ca}^{2+}$ çözeltisi) 
Seçicilik sabiti ölçümleri yapılırken girişim yapan iyonların $1 \times 10^{-6}-1 \times 10^{-1} \mathrm{M}$ arasında değişen standart katyon çözeltileri hazırlanmıştır. Daha sonra, $\mathrm{Ca}^{2+}$-seçici PVC-membran elektrot ile ana iyon çözeltisinin ve girişim yapan iyon çözeltilerinin potansiyometrik ölçümleri alınmıştır. $\mathrm{Ca}^{2+}$-seçici PVC-membran elektrotun farklı iyonlara karşı sergilediği potansiyometrik davranış Şekil 4'te verilmiştir. $\mathrm{Bu}$ çalışmada girișim yapan iyonun $1 \times 10^{-2}$ M'l1k çözeltisinde ölçülen potansiyele eşit potansiyel veren ana iyon çözeltisinin konsantrasyonu belirlenip ayrı çözelti metoduna (SSM, seperate solution method) göre seçicilik sabitleri hesaplanmıştır (IUPAC, 2000).

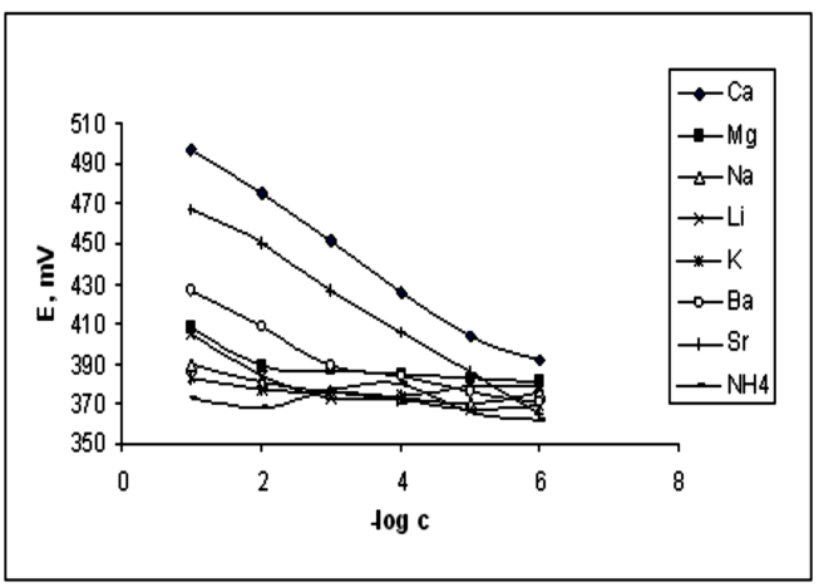

Kalsiyum iyonuna girişim yapma potansiyeli bulunan diğer iyonlara karşı hesaplanan seçicilik sabitleri Çizelge 1'de verilmiştir.

Çizelge 1. $\mathrm{Ca}^{2+}$-seçici PVC-membran elektrotun seçicilik sabitleri

\begin{tabular}{lcc}
\hline Girişim Yapan İyon & $\mathbf{K x}, \mathbf{y}$ & $\log \mathbf{K x}, \mathbf{y}$ \\
\hline $\mathrm{K}^{+}$ & $7,38 \times 10^{-5}$ & $-4,13$ \\
\hline $\mathrm{NH}_{4}{ }^{+}$ & $3,06 \times 10^{-5}$ & $-4,51$ \\
\hline $\mathrm{Li}^{+}$ & $1,47 \times 10^{-4}$ & $-3,83$ \\
\hline $\mathrm{Ba}^{2+}$ & $1,70 \times 10^{-3}$ & $-2,77$ \\
\hline $\mathrm{Mg}^{2+}$ & $2,39 \times 10^{-4}$ & $-3,62$ \\
\hline $\mathrm{Na}^{+}$ & $1,09 \times 10^{-4}$ & $-3,96$ \\
\hline $\mathrm{Sr}^{2+}$ & $9,43 \times 10^{-2}$ & $-1,02$ \\
\hline
\end{tabular}

Hem Şekil 4'ten hem de Çizelge 1'den görüleceği gibi $\mathrm{Ca}^{2+}$-seçici PVC-membran elektrotun diğer iyonlara karşı seçiciliği oldukça iyidir.

Elektrot, sirasiyla $1 \times 10^{-6}-1 \times 10^{-1} \mathrm{M}$ standart $\mathrm{Ca}^{2+}$ çözeltilerine ve $1 \times 10^{-1}-1 \times 10^{-6} \mathrm{M}$ standart $\mathrm{Ca}^{2+}$ çözeltilerine daldırılarak ölçümler alınmıştır (Şekil 5). $1 \times 10^{-4} \mathrm{M} \mathrm{Ca}^{2+}$ çözeltisinden $1 \times 10^{-3} \mathrm{M} \mathrm{Ca}^{2+}$ çözeltisine geçişte elektrotun potansiyelinin dengeye gelme zamanının \%95'ine denk gelen süre hesaplanarak cevap zamanı bulunmuştur. Cevap zaman1, $t_{95}<10$ s olup çok kısadır (IUPAC, 1994).

Şekil 4. $\mathrm{Ca}^{2+}$-seçici PVC-membran elektrotun farklı iyonlara karşı sergilediği potansiyometrik davranışı

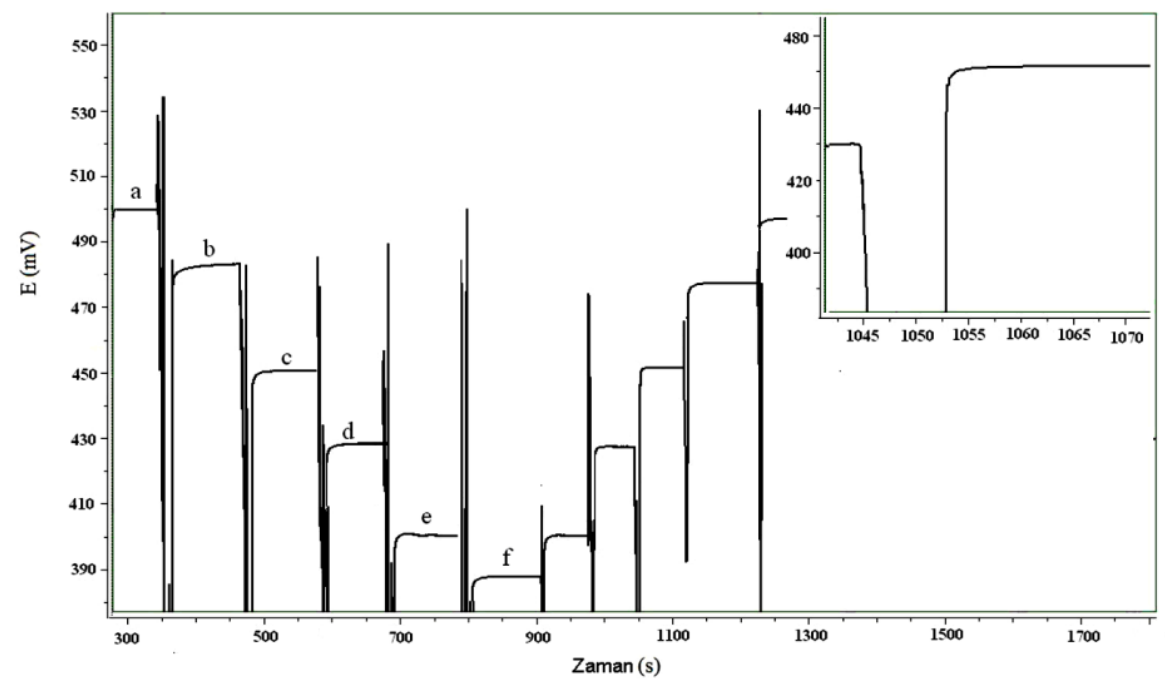

Şekil 5. $\mathrm{Ca}^{2+}$-seçici PVC-membran elektrotun cevap zamanı $\left(\mathrm{a} ; 1 \times 10^{-1} \mathrm{M}, \mathrm{b} ; 1 \times 10^{-2} \mathrm{M}, \mathrm{c} ; 1 \times 10^{-3} \mathrm{M}, \mathrm{d} ; 1 \times 10^{-4} \mathrm{M}\right.$, e; $1 \times 10^{-5} \mathrm{M}, \mathrm{f} ; 1 \times 10^{-6} \mathrm{M} \mathrm{Ca}^{2+}$ çözeltisi) 
Elektrotun doğrusal çalışma aralığ $1 \times 10^{-1}$ ile $1 \times 10^{-5} \mathrm{M}$ arasında değişmektedir. Doğru denklemi ve $\mathrm{R}^{2}$ değeri grafikte verilmiştir. Kalibrasyon grafiğinden tayin limitinin $3,26 \times 10^{-6} \mathrm{M}$ olduğu belirlenmiştir (Şekil 6).

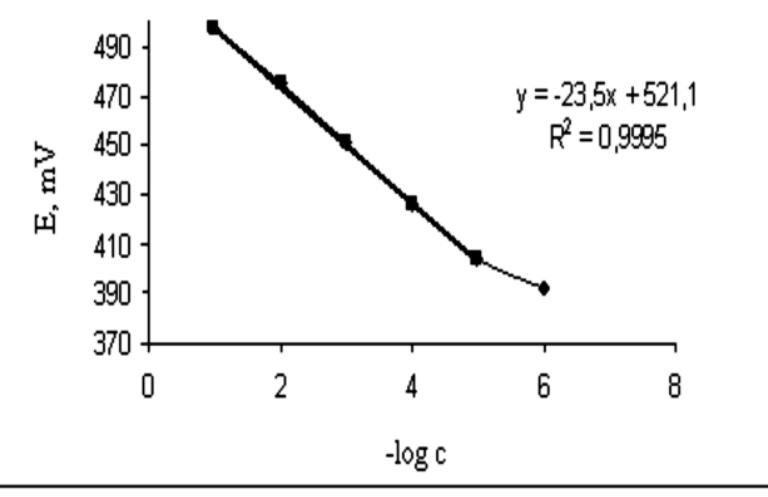

Şekil 6. $\mathrm{Ca}^{2+}$-seçici PVC-membran elektrotun doğrusal çalışma aralığ

Elektrot, $1 \times 10^{-4}, \quad 1 \times 10^{-3}$ ve $1 \times 10^{-2} \mathrm{M}$ lik kalsiyum çözeltilerine sırayla 25 defa daldırılmış ve her bir ölçümden sonra yaklaşık aynı potansiyel değerleri okunmuştur (Şekil 7 ve Çizelge 2). Bu durum elektrotun tekrarlanabilirliğinin iyi olduğunun bir göstergesidir.

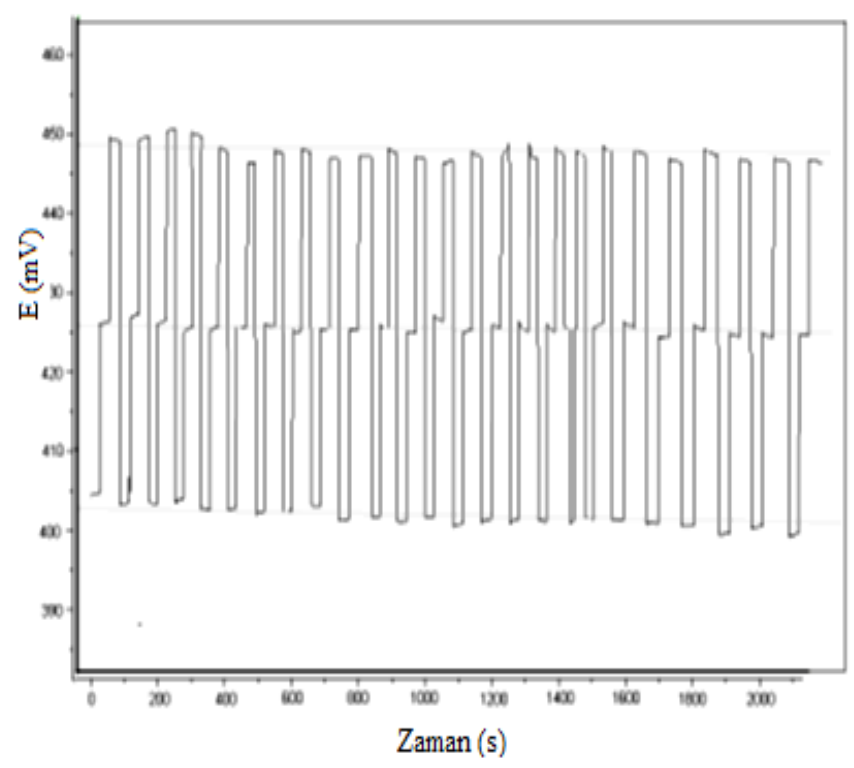

Şekil 7. $\mathrm{Ca}^{2+}$-seçici PVC-membran elektrotun tekrarlanabilirliği
Çizelge 2. $1 \times 10^{-2}, 1 \times 10^{-3}$ ve $1 \times 10^{-4} \mathrm{M} \mathrm{llk} \mathrm{Ca}^{2+}$ çözeltilerine daldırılan elektrotların \% 95 güven aralığında gösterdiği standart sapma ile beraber potansiyel değerleri ve yüzde BSS (N=25)

\begin{tabular}{|c|c|c|c|}
\hline & $\begin{array}{c}1 \times 10^{-2} \mathrm{M} \\
\mathrm{Ca}^{2+}\end{array}$ & $\begin{array}{c}1 \times 10^{-3} \mathrm{M} \\
\mathrm{Ca}^{2+}\end{array}$ & $\begin{array}{c}1 \times 10^{-4} \mathrm{M} \\
\mathrm{Ca}^{2+}\end{array}$ \\
\hline $\begin{array}{l}\text { Potansiyel } \\
(\mathrm{mV})\end{array}$ & $448,4 \pm 4,8^{\mathrm{a}}$ & $426,2 \pm 5,1^{\mathrm{a}}$ & $403,1 \pm 3,7^{\mathrm{a}}$ \\
\hline$\% \mathbf{B S S}^{\mathbf{b}}$ & 1,07 & 1,20 & 0,91 \\
\hline
\end{tabular}

$\mathrm{Ca}^{2+}$-seçici PVC-membran elektrotun $\mathrm{pH}$ çalışma aralığı $\mathrm{pH}$ 'sı 3-10 arasında değişen $1 \times 10^{-3} \mathrm{M}$ ve $1 \times 10^{-4} \mathrm{M}$ sabit $\mathrm{Ca}^{2+}$ içeren $5 \times 10^{-3} \mathrm{M}$ fosfat tamponu çözeltilerinde alınan ölçümlerle belirlenmiştir. Şekil 8 'den de görülebileceği gibi ortamın elektrot, $\quad \mathrm{pH}=4-9$ aralığında ortam pH'sından çok fazla etkilenmeden çalışabilmektedir.

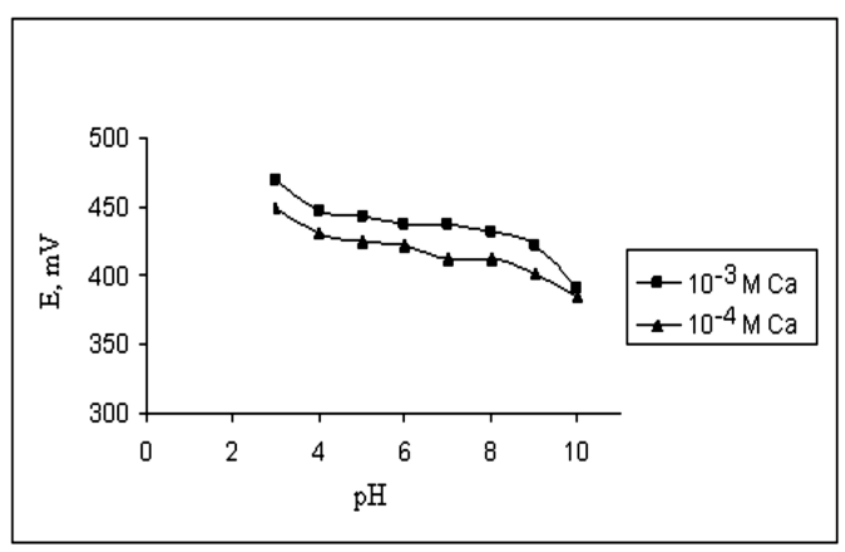

Şekil 8. $\mathrm{Ca}^{2+}$-seçici PVC-Membran elektrotun $\mathrm{pH}$ çalışma aralığ1

$\mathrm{Ca}^{2+}$-seçici PVC-membran elektrotun akış hücreleri hazırlanarak, AEA sisteminde dedektör olarak kullanılmıştır. Hareketli faz olarak $5 \times 10^{-5} \mathrm{CaSO}_{4}$ ve $\mathrm{MgSO}_{4} ; 1 \times 10^{-6} \mathrm{NaCl}, \mathrm{KNO}_{3}, \mathrm{LiNO}_{3}$ ve $\mathrm{NH}_{4} \mathrm{Cl}$ çözelti karışımı kullanılmış, akış hızı: $1,0 \mathrm{~mL}$ dak $^{-1}$ ve enjeksiyon hacmi $20 \mu \mathrm{L}$ olarak optimize edilmiştir. PVC membran hareketli ortam hücreleri ile katyonların değişen derişimlerdeki $\left(1 \times 10^{-1}-1 \times 10^{-5}\right.$ M) standart çözeltilerinin peş peşe ikişer veya üçer kez enjeksiyonu ile AEA sistemine elde edilen flovgram Şekil 9'da görülmektedir. Ayrıca, PVCmembran hareketli ortam hücresi ile AEA sisteminde elde edilen flovgramdaki pik yükseklikleri dikkate alınarak kalsiyum için 


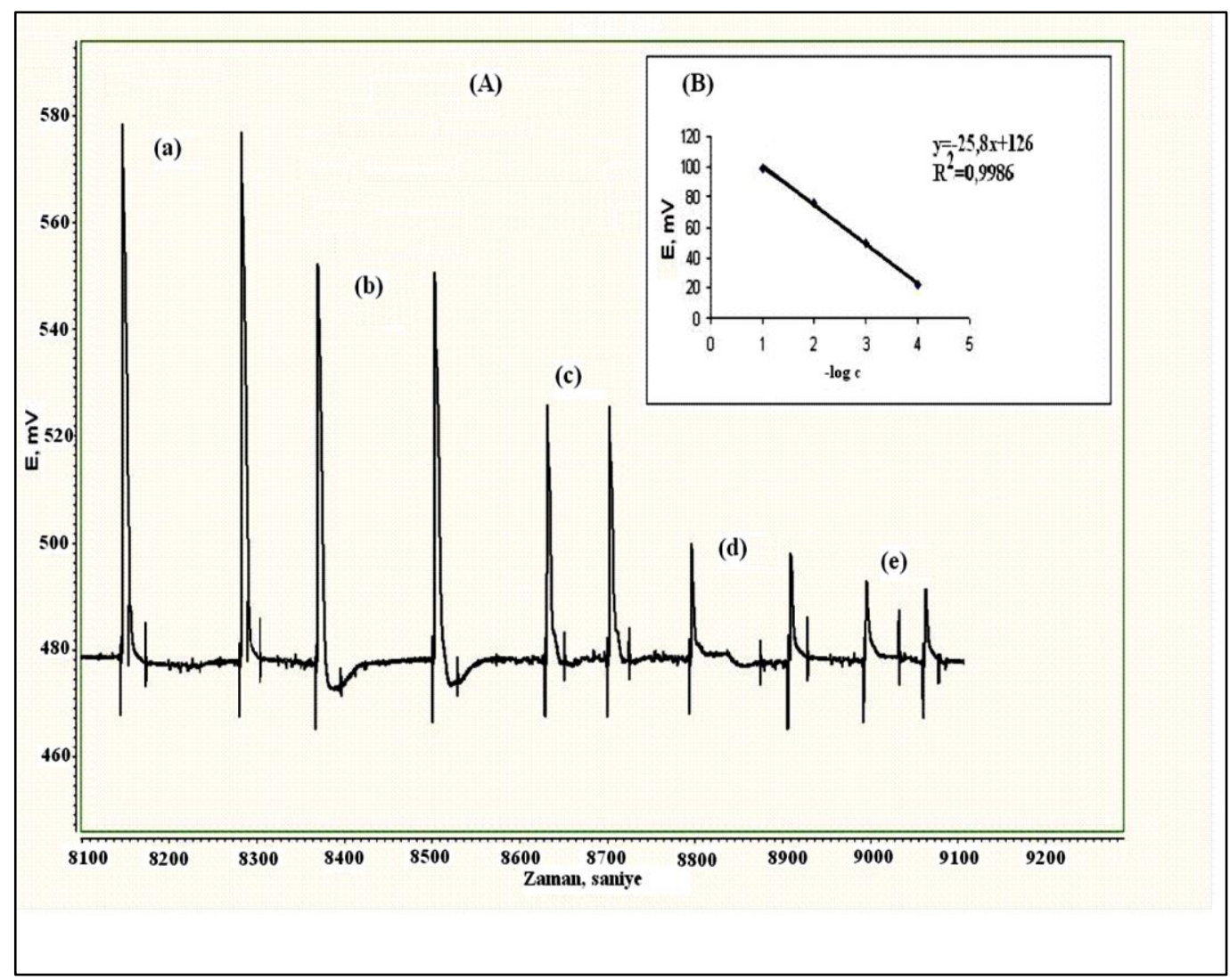

Şekil 9. (A) $\mathrm{Ca}^{2+}$-seçici PVC membran hareketli ortam hücresi ile AEA sisteminde standart $\mathrm{Ca}^{2+}$ çözeltileri için elde edilen pikler (B) $\mathrm{Ca}^{2+}$-seçici PVC membran hareketli ortam hücresi ile AEA sisteminde standart $\mathrm{Ca}^{2+}$ çözeltisi pik yüksekliklerine karşı çizilen kalibrasyon grafiği $\left(\mathrm{a} ; 1 \times 10^{-1} \mathrm{M}, \mathrm{b} ; 1 \times 10^{-2} \mathrm{M}, \mathrm{c} ; 1 \times 10^{-3} \mathrm{M}, \mathrm{d} ; 1 \times 10^{-4} \mathrm{M}, \mathrm{e} ; 1 \times 10^{-5} \mathrm{M}\right.$, Hareketli faz: $5 \times 10^{-5} \mathrm{M} \mathrm{CaSO}_{4}$ ve $\mathrm{MgSO}_{4} ; 1 \times 10^{-6} \mathrm{M} \mathrm{NaCl}, \mathrm{KNO}_{3}, \mathrm{LiNO}_{3}$ ve $\mathrm{NH}_{4} \mathrm{Cl}$ çözelti karışımı, Akış hızı: 1,0 mL dak ${ }^{-1}$, Enjeksiyon hacmi $20 \mu \mathrm{L}$ )

oluşturulan kalibrasyon grafiği de aynı şekil yapılarak

üzerinde gösterilmiştir.

Samsun ilinin farklı bölgelerinden toplanan 5 adet su numunesinde bulunan $\mathrm{Ca}^{2+}$ iyonu, laboratuvarda hazırlanan $\mathrm{Ca}^{2+}$-seçici mikro potansiyometrik PVC-membran elektrotun akış enjeksiyon analiz sisteminde dedektör olarak kullanılması sonucu analiz edilmiştir. Akış enjeksiyon analiz sisteminden standart $\mathrm{Ca}^{2+}$ iyonu için elde edilen pik boyları dikkate alınarak kalibrasyon grafiği çizilmiş ve gerçek numunelerin $20 \mu \mathrm{L}$ 'si sisteme enjekte edilmiş ve elde edilen pik boylarından numunelerdeki $\mathrm{Ca}^{2+}$ derişimleri hesaplanmıştır. Numuneler süzülmüş ve seyreltilmeden kullanılmıştır.

Diğer taraftan, analizi yapılan her bir su numunesine artan derişimlerde standart $\mathrm{Ca}^{2+}$ çözeltisi eklenerek standart çözelti ilavesi yapılmış elde edilen pik boylarından kalibrasyon grafikleri çizilerek numunelerin $\mathrm{Ca}^{2+}$ derişimleri standart ekleme yöntemi ile de bulunmuş, sonuçlar karşılaştırmalı olarak Çizelge 3 'te verilmiştir.

Farklı su numunelerinin kalsiyum içeriği hem laboratuvarda geliştirilen ve akış enjeksiyon sisteminde dedektör olarak kullanılan $\mathrm{Ca}^{2+}$-seçici mikro potansiyometrik PVC-membran elektrot ile hem de standart ekleme yöntemiyle belirlendi. Ayrıca, geliştirilen yöntem için çift taraflı $\mathrm{t}$ testi denemesi yapılmış ve değerler 3.24-3.69 aralığında bulunmuştur. Bulunan bu değerler \%95 güvenirlik düzeyinde verilen tablo değeri ile $\left(\mathrm{t}_{\text {kritik }}=0.05\right)$ karşılaştırılmıştır. 2 Serbestlik derecesi için $t$ tablosunda verilen kritik değer 4.30 dir. Buna göre, bulunan $\mathrm{t}$ değerlerinin tümü verilen bu kritik değerden küçük olduğundan ve standart yönteme 
göre bulunan geri kazanın değerleri dikkate alındığında, geliştirilen $\mathrm{Ca}^{2+}$-seçici mikro Çizelge 3. Akış enjeksiyon analiz yöntemi ve standart ekleme yöntemi ile çevre numunelerinde bulunan $\mathrm{Ca}^{2+}$ derişimleri ${ }^{1}$

\begin{tabular}{|c|c|c|c|c|c|}
\hline Numune & pH & $\begin{array}{c}\text { Akış enjeksiyon analiz } \\
\text { yöntemi }\left(\mathrm{mol} \mathrm{L}^{-1}\right)\end{array}$ & $\begin{array}{c}\text { Standart ekleme } \\
\text { yöntemi }\left(\mathrm{mol} \mathrm{L}^{-1}\right)\end{array}$ & $\begin{array}{r}\% \text { Geri } \\
\text { kazanım }\end{array}$ & $\mathbf{t}_{\text {deneysel }}$ \\
\hline Kürtün 1rmağ1 & 7,34 & $3,14( \pm 0,31) \times 10^{-4}$ & $3,27( \pm 0,27) \times 10^{-4}$ & 104,1 & 3,69 \\
\hline Mert ırmağı & 7,72 & $6,51( \pm 0,53) \times 10^{-4}$ & $6,34( \pm 0,11) \times 10^{-4}$ & 97,4 & 3,57 \\
\hline $\begin{array}{c}\text { Tekkeköy } \\
\text { kaynak suyu }\end{array}$ & 7,15 & $2,64( \pm 0,84) \times 10^{-4}$ & $2,56( \pm 0,37) \times 10^{-4}$ & 96,9 & 3,24 \\
\hline $\begin{array}{l}\text { Tekkeköy dere } \\
\text { suyu }\end{array}$ & 8,12 & $5,32( \pm 0,63) \times 10^{-3}$ & $5,24( \pm 0,28) \times 10^{-3}$ & 98,5 & 3,58 \\
\hline $\begin{array}{l}\text { Kurupelit } \\
\text { içme suyu }\end{array}$ & 7,23 & $7,12( \pm 0,56) \times 10^{-4}$ & $7,05( \pm 0,46) \times 10^{-4}$ & 99,1 & 3,61 \\
\hline
\end{tabular}

potansiyometrik PVC-membran elektrotun dedektör olarak kullanıldığı akış enjeksiyon analiz yöntemi ile standart yöntem (standart ekleme yöntemi) arasında anlamlı bir şekilde fark bulunmadığı ve sonuçların birbiri ile uyumlu olduğunu göstermektedir.

\section{SONUÇ}

Çalışmanın amacı kapsamında, ticari olarak satın alınan iyonofor madde kullanılarak çevre suyu numunelerinde bulunan kalsiyum iyonuna duyarlı $\mathrm{Ca}^{2+}$-seçici mikro potansiyometrik PVC-membran iyon-seçici elektrot geliştirilmiştir. Hazırlanan bu elektrotun potansiyometrik performans karakteristikleri hem durgun ortamda hem de hareketli ortamda incelenmiştir. Daha sonra test edilen elektrot referans elektrotla beraber akış enjeksiyon sisteminde dedektör olarak kullanılmış ve kalsiyum iyonunun gerçek numunelerdeki derişimi hızlı, seçici ve tekrarlanabilir tayinleri başarı ile gerçekleştirilmiştir. Ayrıca, standart yöntem (standart ekleme yöntemi) kullanılarak da gerçek numunelerde ölçümler alınmış ve sonuçlar karşılaştırmalı olarak verilmiştir. Her iki yöntemden elde edilen sonuçlar hem istatistiksel olarak hem de geri kazanım açısından değerlendirilmiş ve sonuçlar arasında anlamlı bir fark bulunmamıştır. Geliştirilen mini büyüklükteki $\mathrm{Ca}^{2+}$-seçici mikro potansiyometrik PVC-membran iyon-seçici elektrot ve bu sensörlere dayalı ölçüm yöntemi basit, kolay ve ekonomiktir. Geliştirilen bu elektrotun dedektör olarak kullanılmasıyla akış enjeksiyon analiz yöntemi ile çevre numunelerindeki $\mathrm{Ca}^{2+}$ iyonunun analizinin rutin olarak yapılabileceği ortaya konmuştur.

\section{KAYNAKLAR}

Abbas, M.N., Magar, H.S., 2018. Highly sensitive and selective solid-contact calcium sensor based on Schiff base of benzil with 3-aminosalycilic acid covalently attached to polyacrylic acid amide for health care. Journal of Solid State Electrochemistry, 22:181-192.

Abramova, N., Moral-Vico, J., Soley, J., Ocana, C., Bratov, A., 2016. Solid contact ion sensor with conducting polymer layer copolymerized with the ion-selective membrane for determination of calcium in blood serum. Analytica Chimica Acta, 943:50-57.

Ahmad, R., Tripathy, N., Ahn, M-S., Yoo, J-Y., Hahn, Y-B., 2018. Preparation of a highly conductive seed layer for calcium sensor fabrication with enhanced sensing performance. ACS Sensors, 3:772-778

Alizadeh, T., Shamkhali, A.N., Hanifehpou, Y., Joo, S.W., 2016. A $\mathrm{Ca}^{2+}$ selective membrane electrode based on calcium-imprinted polymeric nanoparticles. New Journal of Chemistry, 40:84798487.

Amini, M.K., Ghaedi, M., Rafi, A., Habibi, M.H., Zohory, M.M., 2003. Iodide selective electrodes based on bis(2-mercaptobenzothiazolato) mercury(II) and bis(4-chlorothiophenolato) mercury(II) carriers. Sensors, 3(11):509-523.

Bogdanova, A., Makhro, A., Wang, J., Lipp, P., Kaestner, L., 2013. Calcium in red blood cells-a perilous balance. International Journal of Molecular Sciences, 14(5):9848-9872.

Cardwell, T.J., Cattrall, R.W., Hauser, P.C., Hamilton, I.C., 1988. A multi-ion sensor cell and dataacquisition system for flow injection analysis. Analytica Chimica Acta, 214:359-366. 
Cartoni, G.P., Coccioli, F., 1986. Characterization of mineral waters by high-performance liquid chromatography. Journal of Chromatography A, 360:225-230.

de Jesus, A., Zmozinski, A.V., Barbara, J.A., Vale, M.G.R., Silva, M.M., 2010. Determination of calcium and magnesium in biodisel by flame atomic absorption spectrometryusing microemulsions as sample preparation. Energy Fuels, 24:2109-2112.

Deng, B., Zhu, P., Wang, Y., Feng, J., Li, X., Xu, X., Lu, H., Xu, Q., 2008. Determination of free calcium and calcium-containing species in human plasma by capillary electrophoresis-inductively coupled plasma optical emission spectrometry. Analytical Chemistry, 80:5721-5726.

Gallardo, J.S., Alegret M.A.D., Roman, R., Munoz, P.R., Hernandez, L., Leija, L., del Valle M., 2003. Determination of ammonium ion employing an electronic tongue based on potentiometric sensors. Analytical Letters, 36(14):2893-2908.

Gismera, M.J., Arias, S., Sevilla, M.T., Procopio, J.R., 2009. Simultaneous quantification of heavy metals using a solid state potentiometric sensor array. Electroanalysis, 21:979-987.

Gutierrez, M., Alegret, S., Caceres, R., Casadesus, J., Marfa, O., del Valle, M., 2008. Nutrient solution monitoring in greenhouse cultivation employing a potentiometric electronic tongue. Journal of Agricultural and Food Chemistry, 56:1810-1817.

Hans, B.F., 2003. Analysis of water in food by near infrared spectroscopy. Food Chemistry, 82: 107-115.

Hassan, S.S., Sayour, H.E., Al-Mehrezi, S.S., 2007. A novel planar miniaturized potentiometric sensor for flow injection analysis of nitrates in wastewaters, fertilizers and pharmaceuticals. Analytica Chimica Acta, 581:13-18.

Hernandez, R., Riu, J., Rius, F.X., 2010. Determination of calcium ion in sap using carbon nanotube-based ion-selective electrodes. Analyst, 135:1979-1985.

Ismail, A.H., Schäfer, C., Heiss, A., Walter, M., Jahnen-Dechent, W., Leonhardt, S., 2011. An electrochemical impedance spectroscopy (EIS) assay measuring the calcification unhibition capacity in biological fluids. Biosensors and Bioelectronics, 26: 4702-4707.

IUPAC, 1994. Analytical Chemistry Division, Commission on Electroanalytical Chemistry, Recomendations for nomen-clature of Ion-Selective electrodes, Pure and Applied Chemistry, 66:25272536

Johns, V.K., Patel, P.K., Hassett, S., Calvo-Marzal, P., Qin, Y., Chumbimuni-Rius, A., Callao, M., 2001. Application of time series models to the monitoring of a sensor array analytical system. Trends in Analytical Chemistry, 20:168-177.
Lin, M.J., Lewis, M.J., Grandison, A.S., 2006. Measurement of ionic calcium in milk. International Journal of Dairy Technology, 59(3):192-199.

Rius, A., Callao, M., 2001. Application of time series models to the monitoring of a sensor array analytical system, Trends in Analytical Chemistry, 20:168-177.

Ruzicka, J., 1992. The second coming of flow-injection analysis. Analytica Chimica Acta, 261(2):3-10.

Shamsipur, M., Mizani, F., Mousavi, M.F., Alizadeh, N., Alizadeh, K., Eshghi, H. Karami, H., 2007. A novel flow injection potentiometric graphite coated ionselective electrode for the low level determination of uranyl ion. Analytica Chimica Acta, 589:22-32.

Shiddiky, M.J.A., Torriero, A.A.J., 2011. Application of ionic liquids in electrochemical sensing systems. Biosensors and Bioelectronics, 26:1775-1787.

Silanikove, N., Shapiro, F., Shamay, A., 2003. Use of an ion-selective electrode to determine free $\mathrm{Ca}$ ion concentration in the milk of various mammals. Journal of Dairy Research, 70(2):241-243.

Terrab, A., Hernanz, D., Heredia, F.J., 2004 Inductively coupled plasma optical emission spectrometric determination of minerals in thyme honeys and their contributionto geographical discrimination. Journal of Agricultural and Food Chemistry, 52:3441-3445.

Torres, K.Y., 2014. Visible light activated ion sensing using a photoacid polymer for calcium detection. Analytical Chemistry, 86:6184-6187.

Tsioulpas, A., Lewis, M.J., Grandison, A.S., 2007. Effect of minerals on casein micelle stability of cows' milk. Journal of Dairy Research, 74(2):167173.

Zhang, Q., Prabhu, A., San, A., Al-Sharab, J.F., Levon, K., 2015. A polyaniline based ultrasensitive potentiometric immunosensor for cardiac troponin complex detection. Biosensors and Bioelectronics, 72:100-106.

Yang, X., Hibberta, D.B., Alexanderb, P.W., 1998. Flow injection potentiometry by poly(vinyl chloride)membrane electrodes with substituted azacrown ionophores for the determination of lead(II) and mercury(II) ions. Analytica Chimica Acta, 372:387-398. 